\title{
Nonsteroidal Topical Immunomodulators in Allergology and Dermatology
}

\author{
Marina Jovanović and Zoran Golušin \\ Department of Allergy and Clinical Immunology, Clinic of Dermatovenereology Diseases, Clinical Center of Vojvodina, \\ Faculty of Medicine, University of Novi Sad, 21000 Novi Sad, Serbia
}

Correspondence should be addressed to Marina Jovanović; prof.drmarina@gmail.com

Received 21 January 2016; Accepted 22 March 2016

Academic Editor: Alexis Labrada-Rosado

Copyright (C) 2016 M. Jovanović and Z. Golušin. This is an open access article distributed under the Creative Commons Attribution License, which permits unrestricted use, distribution, and reproduction in any medium, provided the original work is properly cited.

The purpose of this study was to review currently available literature data concerning pathomechanisms of action, indications, treatment efficacy, as well as side effects of nonsteroidal immunomodulators used in dermatology, primarily for the treatment of allergic dermatoses. MEDLINE search was undertaken using the key words "Topical Immunomodulators, Dermatology and Allergy". Full articles, and nothing but full articles, were used.

\section{Introduction}

Topical immunomodulators are agents that regulate the local immune response of the skin. Being the largest immune organ, the skin is a target, where in physiological conditions antigen presentation and induction of immune response are in balance. Immunomodulators are indicated if these two immune processes are unbalanced. Compared with systemic immunomodulatory agents, topical immunomodulators show comparable efficacy, ease of application, and greater safety for longer periods without aggressive monitoring. In regard to their mechanism of action, they are either immunostimulatory or immunosuppressive. They are classified into steroidal and nonsteroidal immunomodulatory agents, but generally nonsteroidal topical immunomodulators include the following agents: macrolactams, contact sensitizers, immunostimulants, and miscellaneous agents [1].

\section{Macrolactam Immunomodulators}

2.1. Tacrolimus (FK 506). The word tacrolimus stands for Tsukuba-a geographical region in Japan after which the fungus Streptomyces tsukubaensis was named and from which tacrolimus was isolated [2]. It penetrates the cutaneous barrier to a much greater extent than cyclosporine but is not metabolized locally in the skin. It is only minimally absorbed, with
$0.5 \%$ of the locally applied drug detected in blood, which is undetectable or subtherapeutic [1]. After binding to cytoplasmic immunophilins (known as tacrolimus-binding proteins), tacrolimus acts by selective inhibition of the phosphatase activity of calcineurin, leading to reduced dephosphorylation of the nuclear factor of activated T-cells, inhibiting its translocation into the nucleus, and thus preventing the transcription of several cytokines, including interleukin-2 (IL-2) genes and interferon- $\gamma($ IFN- $\gamma)$ in T-cells [3]. Topical calcineurin inhibitors (TCIs) have been shown to have immunomodulatory effects by inhibiting activation/maturation of Tcells; production of cytokines IL-2, $-4,-5$, tumor necrosis factor- $\alpha$ (TNF- $\alpha$ ), IFN- $\gamma$, granulocyte-macrophage colonystimulating factor (GM-CSF); expression of IL-8 receptors on keratinocytes; decreasing the expression of high-affinity receptor for immunoglobulin E class (FceRI) and CD36 molecules on Langerhans cells (LC) [4]; inhibiting mast cells degranulation [5]; reducing the number of LC and inflammatory dendritic epidermal cells (IDEC) and decreasing the expression of chemokine receptor CCR7 [3]. Tacrolimus restores the epidermal barrier and thus inhibits bronchial hyperactivity and reduces production of immunoglobulins class E (IgE) [6].

Tacrolimus is used in the treatment of atopic dermatitis (AD) (the only one approved by the Food and Drug Administration Agency (FDA)), but it has been effectively used to treat 
psoriasis, pyoderma gangrenosum, lichen planus, graft versus host disease (GVHD), allergic contact dermatitis, rosacea, discoid lupus erythematosus, erythema in a systemic lupus erythematosus (SLE) and dermatomyositis, chronic actinic dermatitis (CAD) [3], allergic asthma, allergic rhinitis and conjunctivitis, vitiligo, and venous ulcerations in rheumatoid arthritis [1]. In children with $\mathrm{AD}, 0.03 \%$ tacrolimus ointment is used twice a day, and $0.1 \%$ ointment is used twice a day in adults during a one-year period of treatment. The efficacy of tacrolimus is comparable to that of the potent topical corticosteroids, for example, $0.12 \%$ betamethasone valerate ointment [7] or mometasone furoate $0.1 \%$ cream (a mid-potent according to the American Contact Dermatitis Society classification) [8]. Tacrolimus ointment does not decrease collagen synthesis of the skin; this is one of its the main advantages compared to topical corticosteroids [7]. Lower efficiency in the treatment of dermatoses with an intact epidermal barrier function can be explained by harder penetration of tacrolimus due to its molecular weight (822 daltons) which is approximately the same as pimecrolimus (811 daltons), but significantly higher than the upper limit necessary for penetration into the skin (500 daltons) [9]. However, recent studies reported a novel modified nanolipid carrier system for topical delivery of tacrolimus (T-MNLC) to be more appealing and beneficial to the patients with better compliance to treating large skin areas of $\mathrm{AD}$ requiring longterm treatment [10].

Tacrolimus has shown encouraging results in the treatment of inverse psoriasis and psoriatic lesions on the face [11].

In the treatment of mucosal erosive lichen planus, tacrolimus has shown a positive therapeutic response [12].

In the management of pyoderma gangrenosum (PG), $0.3 \%$ tacrolimus formulated in carmellose sodium paste in combination with $0.05 \%$ clobetasol propionate ointment; tacrolimus demonstrated good therapeutic efficacy [13] by suppressing neutrophil chemotaxis: suppression of GM-CSF and IL-8. Therapy with topical tacrolimus $0.1 \%$ ointment twice per day resulted in a significant removal of pustular penile PG after 7 days of treatment [14]. In the therapy of localized pyoderma gangrenosum (PGL), 0.1\% tacrolimus ointment ( $2 \mathrm{x}$ per day till resolution, then $1 \mathrm{x}$ a day for 3 months, and $2 x$ per week for $6-12$ months) is the first-line therapy. PGL has been defined by the following criteria: $\leq 5 \%$ of the skin surface affected, $\leq 3$ lesions, short duration, negative microbiological test results, and unknown etiology [15].

Topical $0.1 \%$ tacrolimus ointment with photochemotherapy is suitable adjuvant therapy in the management of erythema and itching in GVHD [16].

Topical $0.075 \%$ tacrolimus ointment shows beneficial effects in the treatment of corticosteroid-induced rosacea, by inhibition of IL- $1 \alpha$ [17].

In the treatment of resistant cutaneous lupus erythematosus in adults, the use of $0.3 \%$ tacrolimus in combination with $0.05 \%$ clobetasol propionate ointment, during 1 month to 6 years, showed few side effects (suppression of glucocorticoidinduced IL- $1 \alpha$ ), but a significantly greater anti-inflammatory effect than with $0.1 \%$ tacrolimus monotherapy [18].

In chronic actinic dermatitis (CAD), tacrolimus decreases the number of LC and DEC, as well as expression of CCR7 with the impeding of antigen presentation and dendritic cells (DC) homing, thus interfering with the induction of delayed-type hypersensitivity reaction (DTH) [3].

In allergic asthma (AS), allergic rhinitis (AR), and allergic conjunctivitis (AC), tacrolimus restores epidermal barrier which results in the reduction of bronchial hyperactivity and IgE production [6]. Tacrolimus is currently available for the topical treatment of severe allergic conjunctivitis. In allergic conjunctivitis and blepharitis tacrolimus does not elevate intraocular pressure; thus it is safer than topical corticosteroids [19].

In vitiligo lesions, it has been shown that tacrolimus increases migration of melanocytes significantly more than ultraviolet UV radiation by the following actions: increase in the activity of metalloproteinases which is significantly higher than when induced by UV; some reduction of synthesis of TNF- $\alpha$ (TNF- $\alpha$ reducing the proliferation of melanocytes) [20]. In combination with a narrow-band UVB phototherapy (NB-UVB), tacrolimus showed synergistic effects [21-23]. In the treatment of vitiligo, tacrolimus is an alternative to corticosteroids (faster repigmentation and absence of atrophy) in children and in lesions on the face, neck, or flexural areas $[24,25]$.

Wound healing in experimental animals has demonstrated that unlike topical corticosteroids (CS), which seemed to delay wound healing, tacrolimus exhibited no negative effects; it increased epithelization, proliferation of fibroblasts, collagen synthesis, and neutrophil polymorphonuclear leukocytes (PMN) infiltration [26].

Successful use of tacrolimus in the treatment of venous ulcerations without secondary infections in rheumatoid arthritis (RA) suggests a role for T-cells in rheumatoid ulcers. Topical tacrolimus inhibits cytokine production and early activation of T-cells; thus it is locally immunomodulating, which could suppress the vasculitis component likely to be involved in ulcers associated with RA and thus promote healing. Another possible mechanism is increased collagen synthesis [27].

Treatment of eosinophilic pustulosis of infancy with topical $0.03 \%$ tacrolimus ointment twice daily (inhibition of Th-2 cytokines) is the first-line therapy [28]. Tacrolimus is safe in children under 2 years of age; a pharmacokinetic multicenter study has been done in $<2$-year-old children which shows no increased serum tacrolimus levels [29]. It has been shown that liposomal formulations of tacrolimus have a 9-fold increase in skin levels compared to the systemic agents [30].

Tacrolimus side effects include burning, erythema, headache, and secondary infections $[1,31,32]$. Topical calcineurin inhibitors (TCIs) were first introduced for the treatment of AD in 1997 [33], with the final beneficial safety concerns announced in 2006 [34].

\subsection{Pimecrolimus (ASM-981). Isolated from Streptomyces} hygroscopicus var. Ascomycetes, pimecrolimus like tacrolimus is a calcineurin inhibitor which inhibits T-cell stimulation by antigen-presenting cells, blocking both T helper cell 1 (Th1) cytokines such as IL-2 and interferon (IFN- $\gamma$ ) and T helper cell 2 (Th2) cytokines including IL-4 10 [1]. It also inhibits 
mast cell release of hexosaminidase, tryptase, and histamine [35]. A recent study done in an oxazolone-induced $\mathrm{AD}$ murine model has shown that topical pimecrolimus, like topical glucocorticoids, improved the AD-like skin lesions and barrier impairment (important for asthma development in AD patients), by suppressing thymic stromal lymphopoietin(TSLP-) related allergic inflammation [36]. TSLP is an epithelial cell-derived IL-7-like cytokine which has an important role in allergic inflammatory immune response, particularly in dendritic cell-mediated allergic inflammation in AS and $\mathrm{AD}$, since it converts human epidermal Langerhans cells into antigen-presenting cells which than induce proallergic Tcells.

Compared to tacrolimus, pimecrolimus shows lower skin penetration [37], higher affinity to epithelial structures, lower affinity to lymphoid structures, lower immunosuppressive effects [38], and threefold lower affinity to macrophilin-12 (FKBP12) [39].

Pimecrolimus is used in the treatment of $\mathrm{AD}$ (the only one indication approved by the FDA), but it has been effectively used to treat erosive oral and genital lichen planus, vulvar lichen sclerosus, Fox-Fordyce disease, intertriginous psoriasis, seborrheic dermatitis, erosive circinate balanitis, discoid lupus erythematosus, vulvar pruritus, vitiligo, and GVHD [40].

In the treatment of $\mathrm{AD}, 1 \%$ pimecrolimus cream, used twice a day, shows the highest efficacy but the similar local tolerability profile in comparison with its $0.05 \%, 0.2 \%$, and $0.6 \%$ concentrations [41]. Pimecrolimus has similar efficacy as low to moderately potent topical corticosteroid creams for mild to moderate $\mathrm{AD}$ during the first 5 to 6 years of life, with similar rates of adverse events [42]. In the treatment of pediatric $\mathrm{AD}$ in a short-term, continuous-use course, pimecrolimus $1 \%$ cream versus tacrolimus $0.03 \%$ ointment has a similar efficiency as assessed by the improvement in the Investigator's Global Assessment (IGA) scale and is equally well tolerated [43].

Topical 1\% pimecrolimus cream used in the treatment of moderate and severe AD in 1.133 children aged 3-23 months up to 2 years showed therapeutic efficacy without increased risk of percutaneous absorption, with no increased incidence of side effects compared to the vehicle alone, without increased incidence of noncutaneous infections compared to the vehicle alone, with no increase in the incidence of skin infections in relation to the vehicle, with no signs of immunosuppression after 2 years of therapy [44].

Nowadays, topical calcineurin inhibitors are primarily used in the treatment of $\mathrm{AD}$, which is not defined as a genetically predisposed dry hypersensitive skin any more, but as acute eczematous skin, which emphasizes the crucial role in skin barrier integrity and extrinsic AD [4547]. Topical therapy includes basic therapy that enhances the restoration and maintenance of the epidermal barrier (hydration, lipid substitution, especially ceramides, wet and occlusive dressings), anti-inflammatory and immunosuppressive therapy which involves application of topical CS, TICs (tacrolimus/pimecrolimus), and tar preparations. Topical anti-inflammatory therapy of the inflamed skin can be reactive, when CSs or calcineurin inhibitors are applied

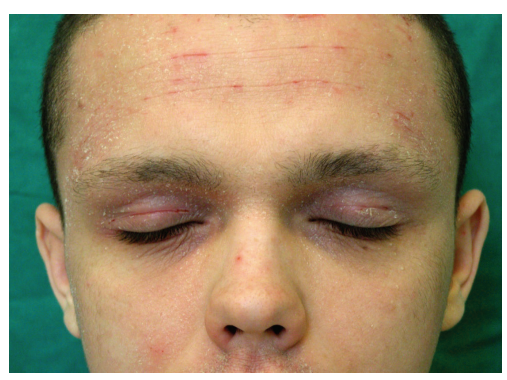

FIGURE 1: Atopic dermatitis on the face before treatment.

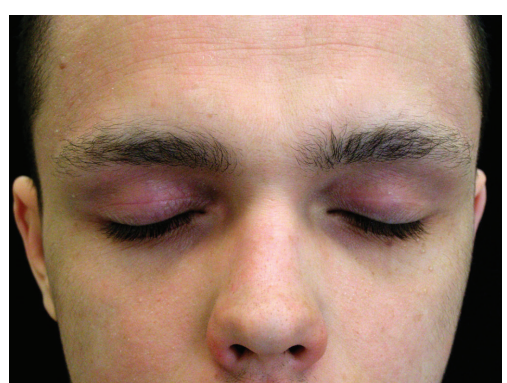

FIGURE 2: Atopic dermatitis on the face seven days after treatment with $1 \%$ pimecrolimus cream.

only on affected skin, and proactive, which is also prophylactic, when the drug is applied intermittently twice a week to those parts of the skin which had previously been affected with simultaneous use of emollients. TCIs tacrolimus/pimecrolimus have been approved by the FDA for the treatment of $\mathrm{AD}$ in individuals aged 2 years and over and in cases that do not require systemic therapy, or the disease showed to be resistant to topical corticosteroids.

The main advantage of this therapy is long-term use at large joint folds, periorbital region, and face, without consequential atrophy, telangiectasia, and striae (Figures 1 and 2). In general, tacrolimus/pimecrolimus should not be used in combination with corticosteroids, whereas photoprotection is an integral part of treatment. Proactive use of pimecrolimus/tacrolimus prevents itching and relapses of mild to moderately severe forms of the disease [45, 48-50].

In February of 2005 (in agreement with topical corticosteroid phobia), FDA issued an alert warning about the possible risks of lymphoma and nonmelanoma skin cancer associated with TCIs, but quite soon, after considerable evaluations, the American Academy of Dermatology Association Task Force has announced that "there is no causal proof that TCIs cause lymphoma or non-melanoma skin cancer" [34]. Moreover, it was only a theoretical assumption that followed the appearance of tumors in experimental animals systemically exposed to high drug concentrations [51]. Aforementioned analyses revealed the following: during three years, 1.7 million people were treated with tacrolimus; 11 lymphomas were detected, none in children; 5 million people were treated with pimecrolimus; and 4 lymphomas, 1 basal cell carcinoma (BCC), and 1 squamous cell carcinoma (SCC) were detected $[52,53]$. The investigation on the safety 
profile of TCIs regarding increased risk for the development of lymphoma was conducted retrospectively evaluating the association between topical immunosuppressants and lymphoma in a cohort study of patients with AD and revealed the following: two hundred and ninety-four cases of lymphoma occurred in 293.253 patients, 81 in patients younger than 20 years; the adjusted analysis yielded OR $(95 \% \mathrm{CI})$ for the following: disease severity (OR 2.4; 95\% CI 1.5-3.8), oral steroids (OR 1.5; CI 1.0-2.4), "superpotent" topical steroids (OR 1.2; 95\% CI 0.8-1.8), "low potency" topical steroids (OR 1.1; 95\% CI 0.7-1.6); pimecrolimus (OR 0.8; 95\% CI 0.4-1.6); tacrolimus (OR 0.8; 95\% CI 0.4-1.7); and concomitant topical steroids, pimecrolimus, and tacrolimus (OR 1.0; 95\% CI 0.34.1). The study revealed no increased risk of lymphoma in patients treated with TCIs [54]. With photoprotection, TCIs have a favorable safety profile without evidence for increased risk for lymphoma [55]. Although there is no evidence of increased risk, clinicians should discuss the various risks with the patient or guardian and document discussion in detail [51].

Pimecrolimus showed a good safety profile in children $>3$ months of age [56-58].

A randomised, double-blind study, conducted in 10 patients using microplaque assay, $0.3 \%$ and $1 \%$ pimecrolimus ointments under occlusion for 2 weeks, showed a comparable efficacy to clobetasol-17-propionate ointment $(0.05 \%)$ [59].

The therapeutic efficacy of pimecrolimus $1 \%$ cream in the treatment of genital lichen sclerosus has been demonstrated to be comparable with an ultrapotent CS, clobetasol-17propionate $0.05 \%$ [60].

In the treatment of seborrheic dermatitis, $1 \%$ cream showed a favorable effect comparable with ketoconazole $2 \%$ cream [61] and betamethasone 17 -valerate $0.1 \%$ cream [62].

2.3. Sirolimus (Rapamycin). Isolated from Streptomyces hygroscopicus in Rapa Nui Island, sirolimus has great immunosuppressive effects building with macrophilin-12 (FKBP12). The target protein of this complex is serine-kinase, "mammalian target of rapamycin (mTOR)" that regulates cell growth. By inhibition of this protease, sirolimus inhibits the cytokine-dependent proliferation of T-cells. In relation to sirolimus, everolimus shows enhanced water solubility because of its additional hydroxy group.

Beneficial therapeutic effects of sirolimus were reported in the treatment of tuberous sclerosis complex (TSC), which results from mutations in a gene or genes that are part of a tumor suppression complex, involving the signal cascade pathway in which the mammalian target of rapamycin (mTOR) is mainly involved. In TSC, the inhibition of mTOR complex-1 is deactivated, leading to an upregulation of mTOR, causing uncontrolled cellular growth, proliferation, and protein synthesis [63]. When used in the treatment of children $\geq 36$ weeks of age, applied once a day, 3 times per week for 9 months, it has shown efficacy in managing the symptoms of TSC through regression of facial angiofibromas [64]. The first case of successful treatment using topical everolimus was published in 2014 [65].
2.4. Cyclosporine. Cyclosporine is a lipophilic cyclic polypeptide isolated from Tolypocladium inflatum gams. Cyclosporine is a prodrug that becomes active only after forming a complex with an intracytoplasmic immunophilin (protein) known as cyclophilin. It showed therapeutic efficacy in cases of refractory standard topical corticosteroid therapy in the following diseases: oral pemphigus $(5 \mathrm{~mL}$ of solution, $100 \mathrm{mg} / \mathrm{mL}, 5$-minute mouthwash 3x/day, 1/day after 6 months); lichen planus (erosive, oral, and vulvar); pyoderma gangrenosum; and benign familial pemphigus [1] . Oral solution $(100 \mathrm{mg} / \mathrm{mL})$ has been shown effectiveness in the treatment of benign familial pemphigus compared to potent corticosteroids [66]. It does not penetrate the skin probably due to larger molecular size. Like tacrolimus, topical cyclosporine is currently available for topical treatment of severe allergic conjunctivitis [19].

\section{Contact Sensitizers}

The immunotherapeutic effectiveness of contact allergens in autoimmune diseases, primarily in alopecia areata (AA), was previously attributed solely to mechanisms of competitive inhibition, while today it is thought to be a consequence of immunomodulation: diphenylcyclopropenone (DPCP) affects T-cell activation and cytokine release [67]; squaric acid dibutyl ester (SADBE) exerts extravasation and recruitment of activated autoreactive T-cells [68].

3.1. Diphenylcyclopropenone. Being recognized as contact allergen with immunomodulating capacity, diphenylcyclopropenone (DPCP) has been widely accepted for the treatment of AA; moreover, it exhibited beneficial effects in patients with common warts as well as metastatic melanomas [1].

In AA, DPCP induces allergic response in $98-99 \%$ and a cosmetically acceptable hair regrowth in $28-80 \%$. Its beneficial effects were in the past exclusively attributed to "competitive antigen inhibition." Not strictly "contact allergic," but also "immunomodulatory" effects [69] can be achieved due to the following DPCP actions: decreasing expression of human leukocyte antigens HLA-ABC and -DR antigens in the epithelium of lower hair follicles; impairing (hair) antigen presentation; and increasing the number of CD8+ lymphocytes (CD8+ Ly). Since CD8+ Ly are considered to be directly involved in hair destruction, their increased number may suggest that during DCP treatment they regain normal reactivity to hair antigens [70]. Generation of T-suppressor CD8 cells within the area treated with DPCP may exert a nonspecific inhibitory effect directed against the autoimmune reaction to an unidentified hair-associated autoantigen, with typical features of contact dermatitis with increased CD8 cells in the inflammatory infiltrate; it seems that DPCP acts by replacing T-cell subsets that have an epithelial cell growth inhibitory cytokine profile such as IFN- $\gamma$ and transforming growth factor $\beta$ (TGF- $\beta$ ), with delayed-type hypersensitivity T-cell subsets that have a stimulatory cytokine profile such as IL-2, IL-8, IL-10, and TNF- $\alpha$ [71]. It has also been shown that, in patients with AA, DPCP shows immunomodulatory effect 
such as increased expression of vascular endothelial growth factor (VEGF) in follicular keratinocytes and endothelial cells in the skin of the affected AA which stimulates angiogenesis and increases the expression of skin-associated chemokine CCL27 (CCL27) on keratinocytes, which stimulates the accumulation of cutaneous lymphocyte-associated antigen (CLA) + T-cell subsets to replace autoreactive (allergen specific) CD4 + T-cell subsets leading to a decrease in the CD4/CD8 ratio [67]. Regarding its side effects, tolerance is produced in 10-12\% after 7-18 months (increasing CD4 + Tcell subsets in infiltrates); it is not recommended for children $<15$ years; contraceptives are mandatory (metabolites have a mutagenic potential).

It is assumed that the mechanism of action which induces positive response of DPCP in the treatment of common warts during $0.5-14$ months on the feet ( $2 \%$ solution in acetone) and hands ( $0.1 \%$ solution in acetone) lies in the reduction in the number of CD $4+\mathrm{T}$-cells and increasing the $\mathrm{CD} 4 / \mathrm{CD} 8$ ratio [1].

The induction of contact sensitization and then allergic contact dermatitis by $0.005 \%-0.01 \%-0.03 \%$ DPCP in aqueous cream showed therapeutic efficacy in the treatment of metastatic cutaneous melanoma without distant metastases, with exclusively cutaneous or local/recurrent or in-transit cutaneous metastases, and refractory melanomas unresponsive to conventional treatment methods. It is assumed that the mechanism of action is based on stimulation of Th17 cellular immune responses [72]. In order to achieve a moderate contact allergic response promptly, $0.01 \%-0.03 \%$ DPCP in aqueous cream was combined with $5 \%$ imiquimod cream 3x week: complete clearance of cutaneous disease was achieved in $46 \%$ and partial response in a further $38 \%$ of patients; mean DPCP treatment duration to clearance of all cutaneous lesions lasted 8 months (range 1-24); and mean duration of complete response was 17 months (range 1-78) [73]. Imiquimod has both immunomodulatory antiviral and antitumor Th1 effects, mediated via activation of Toll-like receptor 7 and 8 and increased production of IFN- $\alpha$, IFN- $\gamma$, TNF- $\alpha$, IL-1, IL-6, IL-8, IL-10, and IL-12 [73] and probably via enhanced inhibition of angiogenesis against micrometastases [74].

3.2. Dinitrochlorobenzene. Allergic contact dermatitis caused by dinitrochlorobenzene (DNCB) has been effectively used in the treatment of nonmelanoma skin cancers (NMSCs): Bowen disease, actinic keratosis, basal cell carcinoma, human immunodeficiency virus (HIV) infection (DNCB modulates Langerhans cell function, which plays an important role in HIV infection), and severe $\mathrm{AD}$ resistant to conventional therapy [75]. It has been suggested that the sensitizing agent in NMSC acts as a hapten and interacts with weak tumor antigens that by themselves are not sufficiently immunogenic to evoke an effective immune response [1].

DNCB contains contaminants that are mutagenic and carcinogenic to animals; when topically applied, more than $40 \%$ of the drug is absorbed systemically. DNCB and mechlorethamine have now largely been replaced by DPC and SADBE in the therapy of AA [76].

\section{Immunostimulators}

4.1. Imiquimod. Imiquimod, a synthetic immunomodulator, has been widely approved for the treatment of actinic keratosis (infiltration CD4+ T-cells), genital warts, and superficial BCC, but its topical application has also been effective in the treatment of common warts, keloids (locally increases IFN- $\alpha$ which than enhances keloidal collagenase activity), molluscum contagiosum infection, extramammary Paget's disease, and lentigo maligna [77].

Imiquimod enhances the innate immune response through binding to Toll-like receptor 7 in the monocytes and macrophages and increasing the production of cytokines: IFN- $\alpha$, TNF- $\alpha$, IL-1, IL-6, IL-8, IL-10, and IL-12. It also stimulates acquired immune response through the stimulation of B-cells, natural killer cells, and migration of LC [1]. Imiquimod 5\% cream has immunoregulatory effects, local antitumor effects, and local antiviral effects. Since imiquimod indirectly stimulates Th- 1 cells to release IFN- $\gamma$, which plays a role in cytotoxic T-cell killing of viral cells [1], it proved successful as adjuvant therapy in the treatment of genital herpes in immunocompromised individuals [78].

4.2. Resiquimod (R-848). Imidazoquinoline amine $0.01 \%$ gel is a potent, soluble analogue of imiquimod. It showed effectiveness in the treatment of recurrent genital herpes by reducing the frequency of mucosal HSV-2 reactivation (genital shedding) [79], but not by reducing acute HSV-2 genital shedding [80].

\section{Miscellaneous Agents}

Miscellaneous topical immunomodulators include calcipotriol, calcitriol, tacalcitol, maxacalcitol, anthralin, zinc, and interferon- $\alpha$ (IFN- $\alpha$, IFN- $\alpha 2 \mathrm{~b})$ [1], while IFN- $\alpha 2 \mathrm{~b}$, IFN- $\beta 1 \mathrm{a}$, and intralesional bacillus Calmette-Guérin are predominantly intralesional recombinant immunomodulators.

5.1. Calcipotriol. Calcipotriol is a synthetic 1,25 -dihydroxyvitamin D3 vitamin analogue which performs its immunomodulatory effects by binding to vitamin D receptors (VDR) present on the keratinocytes, thus inhibiting cellular proliferation and inducing cellular differentiation of these cells; it acts on monocytes, macrophages, and $\mathrm{B}$ and $\mathrm{T}$ lymphocytes to inhibit thymocyte proliferation induced by IL-1 and the release of IL- 6 and IFN- $\gamma$ from activated mononuclear cells; it also reduces the number of infiltrating neutrophils and causes progressive reduction in dermal cellular infiltrate with a shift from CD4+ helper cells to CD8+ suppressor cells [1]. The advantages of topical calcipotriol are as follows: it does not induce skin atrophy or photosensitization; it is well tolerated in children; and it is not teratogenic (elective abortion is not indicated). Its side effect is skin irritation, especially on the face, and it is not routinely recommended to patients with atopic dermatitis, neurodermatitis, or nummular eczema [1].

Calcipotriol $(0.005 \%$ ointment, cream, and solution) showed favorable therapeutic effects in the treatment of 
plaque psoriasis (either alone or as an adjuvant to dithranol, topical steroids, and phototherapy, as twice daily application with maximum weekly application of $100 \mathrm{~g}$ in adults and $50 \mathrm{~g}$ in children); vitiligo (regulates melanin synthesis and restores calcium homeostasis in melanocytes/keratinocytes); keratinization disorders; and miscellaneous skin disorders [1].

Calcipotriol has good therapeutic effects in the treatment of vitiligo combined with NB-UVB therapy [81] or in combination with PUVA (psoralen and ultraviolet irradiation) phototherapy [82] that can be attributed to their synergistic effects. It is assumed that calcipotriol stimulates the expression of endothelin B and stem cell factor/c-kit cytokines, which results in activation of melanocytes and increased tyrosinase activity, and normalizes aberrant calcium homeostasis in keratinocytes and melanocytes present in vitiligo. Its immunomodulatory action is likely mediated by inhibiting the transition of T-cells from early to late G1 phase, which then decreases the synthesis of TNF-a and IFN- $\gamma$ [81].

In regard to keratinization disorders, the literature data obtained from large control studies as well as case reports reported that calcipotriol has also demonstrated its usefulness in the treatment of keratinization disorders other than psoriasis, such as juvenile and adult-onset pityriasis rubra pilaris, inflammatory linear verrucous epidermal nevus, ichthyosis vulgaris, epidermolytic hyperkeratosis, lamellar ichthyosis, Sjögren-Larsson syndrome, ichthyosis linearis circumflexa, X-linked ichthyosis, hereditary palmoplantar keratoderma, acanthosis nigricans, keratosis pilaris, and Darier's disease [1].

5.2. Calcitriol. Hormonally active vitamin D3 [1a,25dihydroxyvitamin $\mathrm{D} 3,1 \mathrm{a}, 25(\mathrm{OH}) 2 \mathrm{D} 3$ ] is a metabolite, also called calcitriol, which is synthesized in keratinocytes. It is available as ointment $(3 \mu \mathrm{g} / \mathrm{g})$; it is suitable for the treatment of psoriasis on the face, neck, and flexural areas, where it exhibits better efficacy than calcipotriol. In the treatment of psoriasis it may be used as monotherapy or as an adjuvant therapy with a topical corticosteroid or UVB phototherapy (the maximum recommended dose of calcitriol ointment should not exceed more than $200 \mathrm{~g}$ per week in adults and $100 \mathrm{~g}$ in children) [83]. In combination with corticosteroids, it reduces their side effects by restoring the following: epidermal permeability by increasing lipids (formation of lipid bodies and the activity of the epidermal lipid synthesis-related enzymes) and antimicrobial barrier (by increasing antimicrobial peptides) [84]. A concentration of $0.1 \mu \mathrm{g} / \mathrm{cm}^{2}$ has a protective function of the UV-damaged skin DNA: it reduces thymine dimers by reducing nitric oxide products and enhances DNA repair by increasing postirradiation levels of $\mathrm{p} 53$. Higher doses $\left(1 \mu \mathrm{g} / \mathrm{cm}^{2}\right)$ induce immunosuppression in the skin (reduced Mantoux response) due to increase of transforming growth factor $\beta$ (TGF- $\beta$ ) in keratinocytes, which results in impaired migration of LC (Langerhans cells); inhibition of LC maturation; suppression of IL-12 production; and enhanced IL-10 production in dendritic cells, including LCs, which results in decreased T-cell activation [85]. Calcitriol is not for oral, ophthalmic, or intravaginal use, and it is not recommended for children younger than 15 years of age, as well as pregnant women [83].

5.3. Tacalcitol. Tacalcitol is a synthetic analogue of 1,25 dihydroxyvitamin D3, available as ointment $(4 \mu \mathrm{g} / \mathrm{g})$; it is used for the treatment of psoriasis, and in combination with NB-UVB phototherapy, applied twice a week, it shows synergism in the treatment of generalized vitiligo by increasing c-Kit mRNA (receptor tyrosine kinase protein in humans encoded by the KIT gene) expression in irradiated melanocytes [86].

5.4. Maxacalcitol. A synthetic analogue of vitamin D3 (1 alpha, 25-dihydroxy-22-oxacalcitriol), maxacalcitol is available as ointment $(0.0025 \%)$; it is used in the treatment of psoriasis as monotherapy, as an adjuvant therapy with NBUVB phototherapy [87], or with cyclosporine A (Cys A), particularly in order to maintain remission [88].

5.5. Anthralin. Anthralin (1,8-dihydroxy-9-anthrone) is an immunomodulator which was previously thought to have only irritant properties in the treatment of AA; it exerts an antimitotic effect by inhibiting DNA synthesis, repair, and replication within keratinocytes, lymphocytes, and fibroblasts; it inhibits mitochondrial metabolism; it also inhibits nicotinamide adenine dinucleotide- (NADH-) dependent isocitrate dehydrogenase; and it decreases cyclic guanosine monophosphate (c-GMP) to normal in keratinocytes. It is available as ointment, cream, or gel (0.1-5\%); a novel dithranol-containing lecithinized microemulsion systems with mean particle diameter of $72.8 \mathrm{~nm}$ composed of isopropyl myristate acetate and polyoxyethylene sorbitan oleate has shown enhanced skin permeation $(82.23 \%)$, skin permeation flux $\left(0.281 \mathrm{mg} / \mathrm{cm}^{2} / \mathrm{h}\right)$ along with skin retention $(8.31 \%)$ and improves topical delivery of dithranol [89].

Anthralin is an effective therapeutic option for limited plaque psoriasis and $\mathrm{AA}$; the advantage of the initial treatment is rapid penetration throughout the epidermis in less than 100 minutes; liposomal aqueous gel-based formulation causes only minimal coloration without irritation [90].

5.6. Zinc. Topical zinc sulphate cream $2.5 \%$ shows antiinflammatory effects by inhibiting release of inflammatory cytokines IL-1 and IL-6 from keratinocytes; combined with $0.05 \%$ clobetasol cream (Zincoderm ${ }^{\circledR}$ cream) it showed good therapeutic effects in the treatment of chronic eczema, eczematous psoriasis, and lichen planus [91]. In eczematous forms of psoriasis, tests related to the mechanisms of development are directed to the investigation of contact sensitization [92]. The formulation with erythromycin $(1.2 \%$ zinc $+4 \%$ erythromycin: Zineryt ${ }^{\circledR}$ solution), besides inhibition of IL-6 release from keratinocytes, lowers 5-alpha reductase in the sebaceous glands, which provides a beneficial effect in the treatment of acne [93].

5.7. Interferon Alpha. Topical IFN $\alpha 2 \mathrm{~b}$ drops $\left(10^{6} \mathrm{IU} / \mathrm{mL}\right)$ were used 4 times per day for four months and demonstrated significant immunomodulating and antiallergic (antianaphylactic) effects in the treatment of vernal keratoconjunctivitis 
by directly inhibiting eosinophil differentiation and proliferation; blocking IgE-mediated histamine release in the tissues; limiting inflammation by inhibiting the release of IL-4 and IL-5 from Th2 cells; inhibiting the release of eosinophilic cationic protein, which plays an important role in the development of corneal damage; inhibiting the release of IL10 from monocytes; and inhibiting overexpressed vascular endothelial growth factor (VEGF) [94]. When applied 4 times a day for 2 months, it showed significant immunomodulatory effects including antiviral, antiproliferative, and angiogenic activities in the treatment of conjunctival and corneal intraepithelial neoplasia [95].

\section{Conclusion}

Regulatory mechanisms of the immune response are numerous; it has been shown that topical immunomodulators interfere in all spheres: from anaphylaxis, eczema, and transplant to tumor immune responses. Once discovered, they have certainly proved their clinical effects, whereas their significance is measured by their therapeutic efficacy. The importance of topical immunomodulators is even greater bearing in mind that the skin is a mirror, and adjacent visible mucous membranes are the window to the human insight.

\section{Abbreviations}

$\begin{array}{ll}\text { IL-2: } & \text { Interleukin-2 } \\ \text { IFN- } \gamma: & \text { Interferon- } \gamma \\ \text { TCIs: } & \text { Topical calcineurin inhibitors } \\ \text { TNF- } \alpha: & \text { Tumor necrosis factor- } \alpha \\ \text { GM-CSF: } & \text { Granulocyte-macrophage colony-stimulating } \\ & \text { factor } \\ \text { FcERI: } & \text { High-affinity receptors for immunoglobulin } \\ & \text { class E } \\ \text { LC: } & \text { Langerhans cells } \\ \text { IDEC: } & \text { Inflammatory dendritic epidermal cells } \\ \text { CCR7: } & \text { Chemokine receptor 7 } \\ \text { IgE: } & \text { Immunoglobulin E } \\ \text { FDA: } & \text { Food and Drug Agency } \\ \text { GVHD: } & \text { Graft versus host disease } \\ \text { IGA: } & \text { Investigator's Global Assessment } \\ \text { SLE: } & \text { Systemic lupus erythematosus } \\ \text { CAD: } & \text { Chronic actinic dermatitis } \\ \text { AD: } & \text { Atopic dermatitis } \\ \text { T-MNLC: } & \text { Modified nanolipid carrier system for topical } \\ & \text { delivery of tacrolimus } \\ \text { PG: } & \text { Pyoderma gangrenosum } \\ \text { PGL: } & \text { Localized pyoderma gangrenosum } \\ \text { DC: } & \text { Dendritic cells } \\ \text { DTH: } & \text { Delayed-type hypersensitivity reaction } \\ \text { AS: } & \text { Allergic asthma } \\ \text { AR: } & \text { Allergic rhinitis } \\ \text { AC: } & \text { Allergic conjunctivitis } \\ \text { CS: } & \text { Corticosteroids } \\ \text { PMNL: } & \text { Polymorphonuclear leukocytes } \\ \text { RA: } & \text { Rheumatoid arthritis } \\ \text { TSLP: } & \text { Thymic stromal lymphopoietin } \\ \text { FKBP12: } & \text { Macrophilin-12 } \\ & \end{array}$

BCC: Basal cell carcinoma

SCC: $\quad$ Squamous cell carcinoma

mTOR: Mammalian target of rapamycin

TSC: Tuberous sclerosis complex

DPCP: Diphenylcyclopropenone

SADBE: Squaric acid dibutyl ester

AA: $\quad$ Alopecia areata

HLA: Human leukocyte antigen

TGF- $\beta$ : Transforming growth factor $\beta$

VEGF: Vascular endothelial growth factor

DNCB: Dinitrochlorobenzene

NMSC: Nonmelanoma skin cancers

HIV: Human immunodeficiency virus

HSV-2: Herpes simplex virus-type 2

VDR: Vitamin D receptors

NB-UVB: Narrow-band ultraviolet B

PUVA: Psoralen and ultraviolet A radiation

Cys A: Cyclosporin A

NADH: Nicotinamide adenine dinucleotide

c-GMP: Cyclic guanosine monophosphate.

\section{Competing Interests}

The authors declare no conflict of interests.

\section{Acknowledgments}

The authors gratefully acknowledge the support of the Ministry of Science and Technological Development of the Republic of Serbia (Project no. 172058). The authors gratefully acknowledge the patient agreement to have his photos displayed in the paper.

\section{References}

[1] S. Khandpur, V. K. Sharma, and K. Sumanth, "Topical immunomodulators in dermatology," Journal of Postgraduate Medicine, vol. 50, no. 2, pp. 131-139, 2004.

[2] J. Berth-Jones, “Topical therapy," in Rook's Textbook of Dermatology, T. Burns, S. Breathnach, N. Cox, and C. Griffiths, Eds., pp. 73.1-73.52, Blackwell, Oxford, UK, 6th edition, 2010.

[3] Y. Ma and Z. Lu, "Treatment with topical tacrolimus favors chronic actinic dermatitis: a clinical and immunopathological study," Journal of Dermatological Treatment, vol. 21, no. 3, pp. 171-177, 2010.

[4] N. Novak, B. Kwiek, and T. Bieber, "The mode of topical immunomodulators in the immunological network of atopic dermatitis," Clinical and Experimental Dermatology, vol. 30, no. 2, pp. 160-164, 2005.

[5] T. Inoue, N. Katoh, and S. Kishimoto, "Prolonged topical application of tacrolimus inhibits immediate hypersensitivity reactions by reducing degranulation of mast cells," Acta Dermato-Venereologica, vol. 86, no. 1, pp. 13-16, 2006.

[6] J. M. Mandelin, A. Remitz, H. M. Virtanen, L. P. Malmberg, T. Haahtela, and S. Reitamo, "A 10-year open follow-up of eczema and respiratory symptoms in patients with atopic dermatitis treated with topical tacrolimus for the first 4 years," Journal of Dermatological Treatment, vol. 21, no. 3, pp. 167-170, 2010.

[7] H. Nakagawa, "Comparison of the efficacy and safety of $0.1 \%$ tacrolimus ointment with topical corticosteroids in adult 
patients with atopic dermatitis: review of randomised, doubleblind clinical studies conducted in Japan," Clinical Drug Investigation, vol. 26, no. 5, pp. 235-246, 2006.

[8] M. A. Khan, L. Khondker, and D. Afroze, "Comparative efficacy of topical mometasone furoate $0.1 \%$ cream vs topical tacrolimus $0.03 \%$ ointment in the treatment of atopic dermatitis," Journal of Pakistan Association of Dermatologists, vol. 24, no. 1, pp. 57-62, 2014.

[9] J. D. Bos and M. M. H. M. Meinardi, "The 500 Dalton rule for the skin penetration of chemical compounds and drugs," Experimental Dermatology, vol. 9, no. 3, pp. 165-169, 2000.

[10] P. V. Pople and K. K. Singh, "Development and evaluation of colloidal modified nanolipid carrier: application to topical delivery of tacrolimus, part II-In vivo assessment, drug targeting, efficacy, and safety in treatment for atopic dermatitis," European Journal of Pharmaceutics and Biopharmaceutics, vol. 84, no. 1, pp. 72-83, 2013.

[11] T. Yamamoto and K. Nishioka, "Topical tacrolimus is effective for facial lesions of psoriasis," Acta Dermato-Venereologica, vol. 80 , no. 6, p. 451, 2000.

[12] C. Vente, K. Reich, R. Rupprecht, and C. Neumann, "Erosive mucosal lichen planus: response to topical treatment with tacrolimus," The British Journal of Dermatology, vol. 140, no. 2, pp. 338-342, 1999.

[13] C. C. Lyon, A. J. Smith, M. H. Beck, G. A. E. Wong, and C. E. M. Griffiths, "Parastomal pyoderma gangrenosum: clinical features and management," Journal of the American Academy of Dermatology, vol. 42, no. 6, pp. 992-1002, 2000.

[14] C. G. Larsen and J. P. Thyssen, "Pustular penile pyoderma gangrenosum successfully treated with topical tacrolimus ointment," Acta Dermato-Venereologica, vol. 92, no. 1, pp. 104-105, 2012.

[15] A. V. Marzano, V. Trevisan, R. Lazzari, and C. Crosti, “Topical tacrolimus for the treatment of localized, idiopathic, newly diagnosed pyoderma gangrenosum," The Journal of Dermatological Treatment, vol. 21, no. 3, pp. 140-143, 2010.

[16] C. J. Choi and P. Nghiem, “Tacrolimus ointment in the treatment of chronic cutaneous graft-vs-host disease: a case series of 18 patients," Archives of Dermatology, vol. 137, no. 9, pp. 12021206, 2001.

[17] Y. Horiuchi, S.-J. Bae, and I. Katayama, "FK506 (tacrolimus) inhibition of intracellular production and enhancement of interleukin $1 \alpha$ through glucocorticoid application to chemically treated human keratinocytes," Skin Pharmacology and Physiology, vol. 18, no. 5, pp. 241-246, 2005.

[18] V. Madan, P. J. August, and R. J. G. Chalmers, "Efficacy of topical tacrolimus $0.3 \%$ in clobetasol propionate $0.05 \%$ ointment in therapy-resistant cutaneous lupus erythematosus: a cohort study," Clinical and Experimental Dermatology, vol. 35, no. 1, pp. 27-30, 2010.

[19] A. T. Kelmenson, N. K. Rao, and M. B. Raizman, "Treatment of allergic eye diaseases," in Ocular Surface Disease: Cornea, Conjunctiva and Tear Film, E. J. Holland, M. J. Mannis, and W. B. Lee, Eds., pp. 117-124, Elsevier Saunders, London, UK, 6th edition, 2013.

[20] K. Y. Lee, S. Y. Jeon, J. W. Hong et al., "Endothelin-1 enhances the proliferation of normal human melanocytes in a paradoxical manner from the TNF- $\alpha$-inhibited condition, but tacrolimus promotes exclusively the cellular migration without proliferation: a proposed action mechanism for combination therapy of phototherapy and topical tacrolimus in vitiligo treatment," Journal of the European Academy of Dermatology and Venereology, vol. 27, no. 5, pp. 609-616, 2013.

[21] I. Majid, "Does topical tacrolimus ointment enhance the efficacy of narrowband ultraviolet B therapy in vitiligo? A leftright comparison study," Photodermatology Photoimmunology \& Photomedicine, vol. 26, no. 5, pp. 230-234, 2010.

[22] H. Satyanarayan, A. Kanwar, D. Parsad, and K. Vinay, "Efficacy and tolerability of combined treatment with NB-UVB and topical tacrolimus versus NB-UVB alone in patients with vitiligo vulgaris: a randomized intra-individual open comparative trial," Indian Journal of Dermatology, Venereology and Leprology, vol. 79, no. 4, pp. 525-527, 2013.

[23] C. Pagliarello and A. Paradisi, "Topical tacrolimus is useful for avoiding suction-blister epidermal grafting depigmentation in non-segmental vitiligo: a case report," Acta DermatoVenereologica, vol. 92, no. 2, pp. 181-182, 2012.

[24] C. W. Choi, S. E. Chang, H. Bak et al., "Topical immunomodulators are effective for treatment of vitiligo," The Journal of Dermatology, vol. 35, no. 8, pp. 503-507, 2008.

[25] E. J. Nordal, G. E. Guleng, and J. R. Rönnevig, "Treatment of vitiligo with narrowband-UVB (TL01) combined with tacrolimus ointment $(0.1 \%)$ vs. placebo ointment, a randomized right/left double-blind comparative study," Journal of the European Academy of Dermatology and Venereology, vol. 25, no. 12, pp. 1440-1443, 2011.

[26] S. Namkoong, J. Chung, J. Yoo et al., “Topical tacrolimus does not negatively impact acute skin wound healing," Experimental Dermatology, vol. 22, no. 5, pp. 369-371, 2013.

[27] J. M. Mandelin, K. K. Eklund, and S. Reitamo, "Leg ulcers treated with topical tacrolimus in patients with rheumatoid arthritis," Acta Dermato-Venereologica, vol. 90, no. 6, pp. 633634, 2010.

[28] N. P. Patel, B. Laguda, N. M. Roberts, N. D. Francis, and K. Agnew, "Treatment of eosinophilic pustulosis of infancy with topical tacrolimus," British Journal of Dermatology, vol. 167, no. 5, pp. 1189-1191, 2012.

[29] T. S. Housman, A. B. Norton, S. R. Feldman et al., "Tacrolimus ointment: utilization patterns in children under age 2 years," Dermatology Online Journal, vol. 10, no. 1, p. 2, 2004.

[30] M. Erdogan, J. R. Wright Jr., and V. C. McAlister, "Liposomal tacrolimus lotion as a novel topical agent for treatment of immune-mediated skin disorders: experimental studies in a murine model," The British Journal of Dermatology, vol. 146, no. 6, pp. 964-967, 2002.

[31] S.-L. Chen, J. Yan, and F.-S. Wang, "Two topical calcineurin inhibitors for the treatment of atopic dermatitis in pediatric patients: a meta-analysis of randomized clinical trials," The Journal of Dermatological Treatment, vol. 21, no. 3, pp. 144-156, 2010.

[32] S. Reitamo, J. P. Ortonne, C. Sand et al., "A multicentre, randomized, double-blind, controlled study of long-term treatment with $0.1 \%$ tacrolimus ointment in adults with moderate to severe atopic dermatitis," The British Journal of Dermatology, vol. 152, no. 6, pp. 1282-1289, 2005.

[33] T. Ruzicka, T. Bieber, E. Schöpf et al., "A short-term trial of tacrolimus ointment for atopic dermatitis," The New England Journal of Medicine, vol. 337, no. 12, pp. 816-821, 1997.

[34] T. G. Berger, M. Duvic, A. S. van Voorhees, and I. J. Frieden, "The use of topical calcineurin inhibitors in dermatology: safety concerns. Report of the American Academy of Dermatology 
Association Task Force," Journal of the American Academy of Dermatology, vol. 54, no. 5, pp. 818-823, 2006.

[35] T. Hultsch, K. D. Müller, J. G. Meingassner, M. Grassberger, R. E. Schopf, and J. Knop, "Ascomycin macrolactam derivative SDZ ASM 981 inhibits the release of granule-associated mediators and of newly synthesized cytokines in RBL 2H3 mast cells in an immunophilin-dependent manner," Archives of Dermatological Research, vol. 290, no. 9, pp. 501-507, 1998.

[36] N. Y. Yoon, M. Y. Jung, D. H. Kim, H. J. Lee, and E. H. Choi, "Topical glucocorticoid or pimecrolimus treatment suppresses thymic stromal lymphopoietin-related allergic inflammatory mechanism in an oxazolone-induced atopic dermatitis murine model," Archives of Dermatological Research, vol. 307, no. 7, pp. 569-581, 2015.

[37] A. Billich, H. Aschauer, A. Aszódi, and A. Stuetz, "Percutaneous absorption of drugs used in atopic eczema: pimecrolimus permeates less through skin than corticosteroids and tacrolimus," International Journal of Pharmaceutics, vol. 269, no. 1, pp. 29-35, 2004.

[38] A. S. Paller, M. Lebwohl, A. B. Fleischer Jr. et al., "Tacrolimus ointment is more effective than pimecrolimus cream with a similar safety profile in the treatment of atopic dermatitis: results from 3 randomized, comparative studies," Journal of the American Academy of Dermatology, vol. 52, no. 5, pp. 810-822, 2005.

[39] S. Reitamo, A. Remitz, H. Kyllönen, and J. Saarikko, "Topical noncorticosteroid immunomodulation in the treatment of atopic dermatitis," American Journal of Clinical Dermatology, vol. 3, no. 6, pp. 381-388, 2002.

[40] V. N. Sehgal and M. Pahwa, "Pimecrolimus, yet another intriguing topical immunomodulator," The Journal of Dermatological Treatment, vol. 18, no. 3, pp. 147-150, 2007.

[41] T. Luger, E. J. M. Van Leent, M. Graeber et al., "SDZ ASM 981: an emerging safe and effective treatment for atopic dermatitis," The British Journal of Dermatology, vol. 144, no. 4, pp. 788-794, 2001.

[42] B. Sigurgeirsson, A. Boznanski, G. Todd et al., "Safety and efficacy of pimecrolimus in atopic dermatitis: a 5-year randomized trial," Pediatrics, vol. 135, no. 4, pp. 597-606, 2015.

[43] L. P. H. Yang and M. P. Curran, "Spotlight on topical pimecrolimus in pediatric atopic dermatitis," American Journal of Clinical Dermatology, vol. 11, no. 4, pp. 295-298, 2010.

[44] C. Paul, M. Cork, A. B. Rossi, K. A. Papp, N. Barbier, and Y. de Prost, "Safety and tolerability of $1 \%$ pimecrolimus cream among infants: experience with 1133 patients treated for up to 2 years," Pediatrics, vol. 117, no. 1, pp. el18-e128, 2006.

[45] J. Ring, A. Alomar, T. Bieber et al., "Guidelines for treatment of atopic eczema (atopic dermatitis) Part II," Journal of the European Academy of Dermatology and Venereology, vol. 26, no. 9, pp. 1176-1193, 2012.

[46] M. A. Jovanović, M. Poljački, N. Mimica-Dukić et al., "Sesquiterpene lactone mix patch testing supplemented with dandelion extract in patients with allergic contact dermatitis, atopic dermatitis and non-allergic chronic inflammatory skin diseases," Contact Dermatitis, vol. 51, no. 3, pp. 101-110, 2004.

[47] M. Jovanović, "Manifestations of contact allergy," Srpski Arhiv za Celokupno Lekarstvo, vol. 140, no. 11-12, pp. 786-791, 2012.

[48] A. Wollenberg, R. Frank, J. Kroth, and T. Ruzicka, "Proactive therapy of atopic eczema-an evidence based concept with a behavioral background," Journal der Deutschen Dermatologischen Gesellschaft, vol. 7, no. 2, pp. 117-121, 2009.
[49] U. Darsow, K. Eyerich, and J. Ring, Eczema (E), Atopic Eczema $(A E)$ and Atopic Dermatitis (AD), World Allergy Organization, 2016, http://www.worldallergy.org/professional/allergic_diseases_center/atopiceczema/.

[50] M. Jovanović, "Current concepts of pathophysiology, epidemiology and classification of pruritus," Srpski Arhiv za Celokupno Lekarstvo, vol. 142, no. 1-2, pp. 106-112, 2014.

[51] T. S. Patel, S. C. Greer, and R. B. Skinner Jr., "Cancer concerns with topical immunomodulators in atopic dermatitis: overview of data and recommendations to clinicians," American Journal of Clinical Dermatology, vol. 8, no. 4, pp. 189-194, 2007.

[52] Fujisawa Healthcare, "Background package," in Proceedings of the Meeting of the Pediatric Advisory Committee of the US Food and Drug Administration, Washington, DC, USA, February 2005.

[53] T. Hultsch, "Elidel ${ }^{\circledR}$ (pimecrolimus) cream 1\% safety," in Proceedings of the Meeting of the Pediatric Advisory Committee of the US Food and Drug Administration, Washington, DC, USA, February 2005.

[54] F. M. Arellano, C. E. Wentworth, A. Arana, C. Fernández, and C. F. Paul, "Risk of lymphoma following exposure to calcineurin inhibitors and topical steroids in patients with atopic dermatitis," The Journal of Investigative Dermatology, vol. 127, no. 4, pp. 808-816, 2007.

[55] S. G. Plötz and J. Ring, "What's new in atopic eczema?" Expert Opinion on Emerging Drugs, vol. 15, no. 2, pp. 249-267, 2010.

[56] J. Harper, A. Green, G. Scott et al., "First experience of topical SDZ ASM 981 in children with atopic dermatitis," The British Journal of Dermatology, vol. 144, no. 4, pp. 781-787, 2001.

[57] A. Kapp, K. Papp, A. Bingham et al., "Long-term management of atopic dermatitis in infants with topical pimecrolimus, a nonsteroid anti-inflammatory drug," The Journal of Allergy and Clinical Immunology, vol. 110, no. 2, pp. 277-284, 2002.

[58] T. Luger and A. Nieto, "Pimecrolimus cream $1 \%$ in infants with mild-to moderate atopic dermatitis: efficacy and safety results from a 5-year randomized study," in 21th Congress of the EADV (27-30 Sep 2012 Praque Czech Republik), PRA 12-0252, European Academy of Dermatology and Venerology, 2012.

[59] U. Mrowietz, M. Graeber, M. Bräutigam et al., "The novel ascomycin derivative SDZ ASM 981 is effective for psoriasis when used topically under occlusion," British Journal of Dermatology, vol. 139, no. 6, pp. 992-996, 1998.

[60] A. T. Goldstein, A. Creasey, R. Pfau, D. Phillips, and L. J. Burrows, "A double-blind, randomized controlled trial of clobetasol versus pimecrolimus in patients with vulvar lichen sclerosus," Journal of the American Academy of Dermatology, vol. 64, no. 6, pp. e99-e104, 2011.

[61] E. Koc, E. Arca, O. Kose, and A. Akar, "An open, randomized, prospective, comparative study of topical pimecrolimus $1 \%$ cream and topical ketoconazole $2 \%$ cream in the treatment of seborrheic dermatitis," The Journal of Dermatological Treatment, vol. 20, no. 1, pp. 4-9, 2009.

[62] D. Rigopoulos, D. Ioannides, D. Kalogeromitros, S. Gregoriou, and A. Katsambas, "Pimecrolimus cream $1 \%$ vs. betamethasone 17 -valerate $0.1 \%$ cream in the treatment of seborrhoeic dermatitis. A randomized open-label clinical trial," The British Journal of Dermatology, vol. 151, no. 5, pp. 1071-1075, 2004.

[63] B. Madke, "Topical rapamycin (sirolimus) for facial angiofibromas," Indian Dermatology Online Journal, vol. 4, no. 1, pp. 54-57, 2013.

[64] R. Salido, G. Garnacho-Saucedo, I. Cuevas-Asencio et al., "Sustained clinical effectiveness and favorable safety profile 
of topical sirolimus for tuberous sclerosis-associated facial angiofibroma," Journal of the European Academy of Dermatology and Venereology, vol. 26, no. 10, pp. 1315-1318, 2012.

[65] P. E. Dill, G. de Bernardis, P. Weber, and U. Lösch, “Topical everolimus for facial angiofibromas in the tuberous sclerosis complex. A first case report," Pediatric Neurology, vol. 51, no. 1, pp. 109-113, 2014.

[66] K. Jitsukawa, J. Ring, U. Weyer, W. Kimmig, and H. Radloff, "Topical cyclosporine in chronic benign familial pemphigus (Hailey-Hailey disease)," Journal of the American Academy of Dermatology, vol. 27, no. 4, pp. 625-626, 1992.

[67] O. Simonetti, G. Lucarini, M. L. Bernardini, C. Simoncini, G. Biagini, and A. Offidani, "Expression of vascular endothelial growth factor, apoptosis inhibitors (survivin and p16) and CCL27 in alopecia areata before and after diphencyprone treatment: an immunohistochemical study," The British Journal of Dermatology, vol. 150, no. 5, pp. 940-948, 2004.

[68] M. Zöller, P. Freyschmidt-Paul, M. Vitacolonna, K. J. McElwee, S. Hummel, and R. Hoffmann, "Chronic delayed-type hypersensitivity reaction as a means to treat alopecia areata," Clinical and Experimental Immunology, vol. 135, no. 3, pp. 398-408, 2004.

[69] D. Wasserman, D. A. Guzman-Sanchez, K. Scott, and A. McMichael, "Alopecia areata," International Journal of Dermatology, vol. 46, no. 2, pp. 121-131, 2007.

[70] T. Wasyłyszyn, W. Kozłowski, and S. L. Zabielski, "Changes in distribution pattern of CD8 lymphocytes in the scalp in alopecia areata during treatment with diphencyprone," Archives of Dermatological Research, vol. 299, no. 5-6, pp. 231-237, 2007.

[71] N. Hunter, O. Shaker, and N. Marei, "Diphencyprone and topical tacrolimus as two topical immunotherapeutic modalities. Are they effective in the treatment of alopecia areata among Egyptian patients? A study using CD4, CD8 and MHC II as markers," The Journal of Dermatological Treatment, vol. 22, no. 1, pp. 2-10, 2011.

[72] Y. J. Kim, “Topical diphencyprone as an effective treatment for cutaneous metastatic melanoma," Annals of Dermatology, vol. 24, no. 3, pp. 373-375, 2012.

[73] D. L. Damian, R. P. M. Saw, and J. F. Thompson, “Topical immunotherapy with diphencyprone for in transit and cutaneously metastatic melanoma," Journal of Surgical Oncology, vol. 109, no. 4, pp. 308-313, 2014.

[74] I. Savarese, F. Papi, A. D’Errico et al., “Acral lentiginous melanoma treated with topical imiquimod cream: possible cooperation between drug and tumour cells," Clinical and Experimental Dermatology, vol. 40, no. 1, pp. 27-30, 2015.

[75] L. B. Mills, L. J. Mordan, H. L. Roth, E. E. Winger, and W. L. Epstein, "Treatment of severe atopic dermatitis by topical immune modulation using dinitrochlorobenzene," Journal of the American Academy of Dermatology, vol. 42, no. 4, pp. 687689, 2000.

[76] P. V. Harrison, J. Latona, and M. Jovanovic, "Alopecia totalis and topical mustine," Archives of Dermatology, vol. 129, no. 4, article 514, 1993.

[77] I. Ahmed and J. Berth-Jones, "Imiquimod: a novel treatment for lentigo maligna," British Journal of Dermatology, vol. 143, no. 4, pp. 843-845, 2000 .

[78] N. Bangsgaard and L. Skov, "Chronic genital ulceration due to herpes simplex infection treated successfully with imiquimod," Acta Dermato-Venereologica, vol. 88, no. 2, pp. 202-203, 2008.
[79] K. E. Mark, L. Corey, T.-C. Meng et al., “Topical resiquimod $0.01 \%$ gel decreases herpes simplex virus type 2 genital shedding: a randomized, controlled trial," The Journal of Infectious Diseases, vol. 195, no. 9, pp. 1324-1331, 2007.

[80] K. H. Fife, T.-C. Meng, D. G. Ferris, and P. Liu, "Effect of resiquimod $0.01 \%$ gel on lesion healing and viral shedding when applied to genital herpes lesions," Antimicrobial Agents and Chemotherapy, vol. 52, no. 2, pp. 477-482, 2008.

[81] G. Khullar, A. J. Kanwar, S. Singh, and D. Parsad, “Comparison of efficacy and safety profile of topical calcipotriol ointment in combination with NB-UVB vs. NB-UVB alone in the treatment of vitiligo: a 24-week prospective right-left comparative clinical trial," Journal of the European Academy of Dermatology and Venereology, vol. 29, no. 5, pp. 925-932, 2015.

[82] A. A. Mohamed and S. F. El-Saman, "Light and electron microscopic studies of the effect of combined topical calcipotriol and PUVA therapy on patients with vitiligo," The Egyptian Journal of Histology, vol. 34, no. 1, pp. 15-27, 2011.

[83] J. Q. del Rosso and G. K. Kim, “The rationale behind topical vitamin $\mathrm{D}$ analogs in the treatment of psoriasis. Where does topical calcitriol fit in?" Journal of Clinical and Aesthetic Dermatology, vol. 3, no. 8, pp. 46-53, 2010.

[84] S. P. Hong, Y. Oh, M. Jung et al., "Topical calcitriol restores the impairment of epidermal permeability and antimicrobial barriers induced by corticosteroids," The British Journal of Dermatology, vol. 162, no. 6, pp. 1251-1260, 2010.

[85] D. L. Damian, Y. J. Kim, K. M. Dixon, G. M. Halliday, A. Javeri, and R. S. Mason, "Topical calcitriol protects from UVinduced genetic damage but suppresses cutaneous immunity in humans," Experimental Dermatology, vol. 19, no. 8, pp. e23-e30, 2010.

[86] G. Leone, A. Pacifico, P. Iacovelli, A. P. Vidolin, and M. Picardo, "Tacalcitol and narrow-band phototherapy in patients with vitiligo," Clinical and Experimental Dermatology, vol. 31, no. 2, pp. 200-205, 2006.

[87] T. Takekoshi, A. Asahina, M. Komine, and K. Tamaki, "Treatment of psoriasis vulgaris with narrow-band UVB and topical maxacalcitol," Acta Dermato-Venereologica, vol. 86, no. 4, pp. 375-376, 2006.

[88] M. Abe, T. Syuto, M. Hasegawa, Y. Yokoyama, and O. Ishikawa, "Clinical usefulness of a supplementary cyclosporin administration with a topical application of maxacalcitol ointment for patients with moderate psoriasis vulgaris," The Journal of Dermatology, vol. 36, no. 4, pp. 197-201, 2009.

[89] K. Raza, P. Negi, S. Takyar, A. Shukla, B. Amarji, and O. P. Katare, "Novel dithranol phospholipid microemulsion for topical application: development, characterization and percutaneous absorption studies," Journal of Microencapsulation, vol. 28, no. 3, pp. 190-199, 2011.

[90] R. Agarwal, A. Saraswat, I. Kaur, O. P. Katare, and B. Kumar, "A novel liposomal formulation of dithranol for psoriasis: preliminary results," The Journal of Dermatology, vol. 29, no. 8, pp. 529-532, 2002.

[91] J. Thomas, S. Kandhari, C. Oberoi, E. Jayaseelan, and K. Yogi Raj, "A double-blind randomized multicentre controlled study of topical $0.05 \%$ clobetasol propionate with $2.5 \%$ zinc sulphate preparation," Indian Journal of Dermatology Venereology and Leprology, vol. 67, no. 5, pp. 135-137, 2001.

[92] M. Jovanović, P. Boża, D. Karadaglić et al., "Contact sensitivity in patients with psoriasis in Vojvodina," International Archives of Allergy and Immunology, vol. 148, no. 4, pp. 311-320, 2009. 
[93] F. Dalgard, U. Gieler, J. Ø. Holm, E. Bjertness, and S. Hauser, "Self-esteem and body satisfaction among late adolescents with acne: results from a population survey," Journal of the American Academy of Dermatology, vol. 59, no. 5, pp. 746-751, 2008.

[94] E. Turan-Vural, B. T. Acar, and S. Acar, "The efficacy of topical interferon alpha $2 \mathrm{~b}$ treatment in refractory vernal keratoconjunctivitis," Ocular Immunology and Inflammation, vol. 20, no. 2, pp. 125-129, 2012.

[95] V. Huerva and I. Mangues, "Treatment of conjunctival squamous neoplasias with interferon alpha 2b," Journal Francais d'Ophtalmologie, vol. 31, no. 3, pp. 317-325, 2008. 


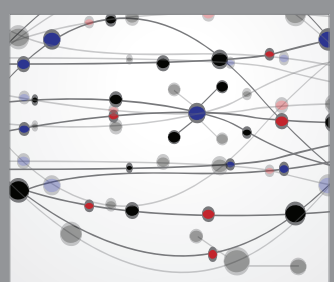

The Scientific World Journal
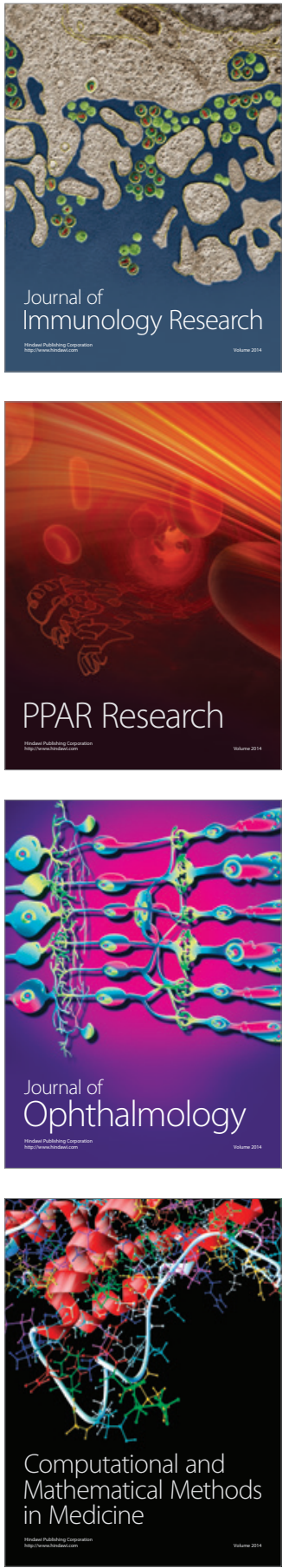

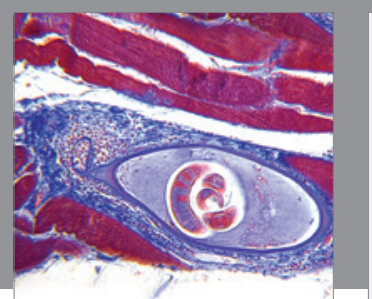

Gastroenterology Research and Practice

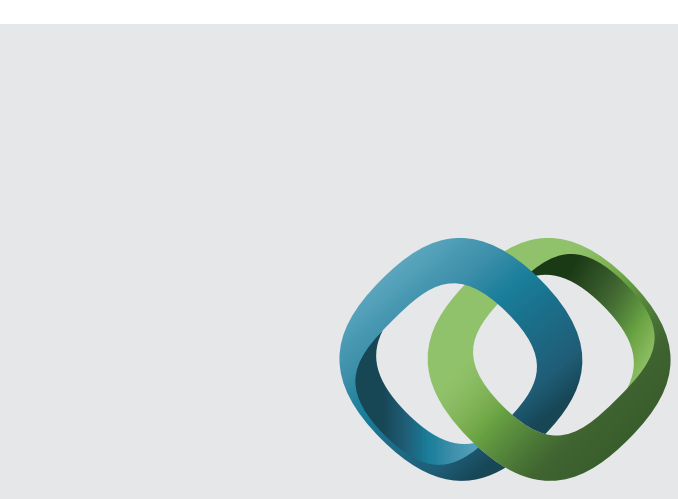

\section{Hindawi}

Submit your manuscripts at

http://www.hindawi.com
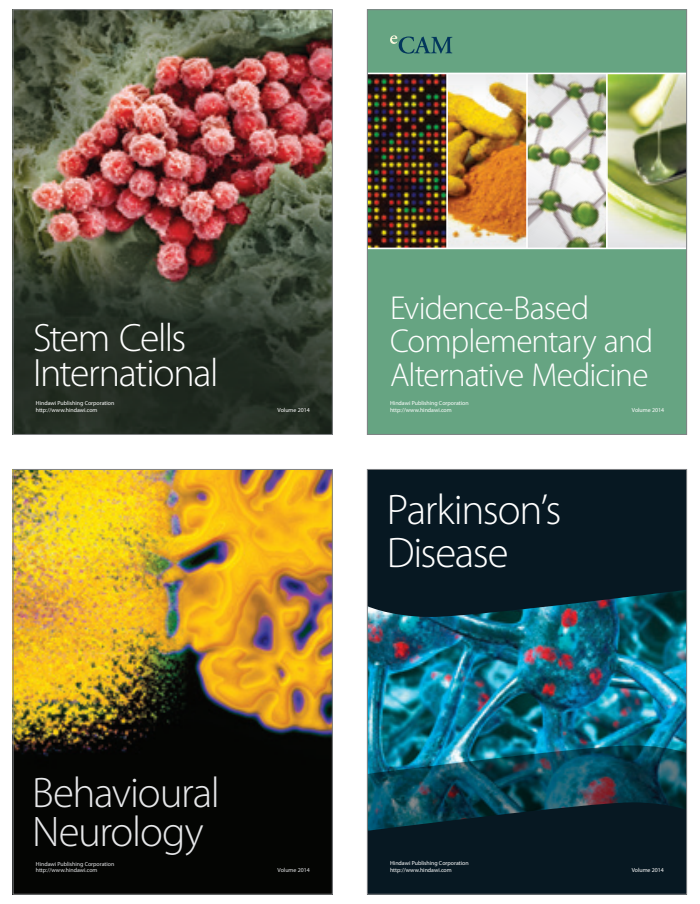
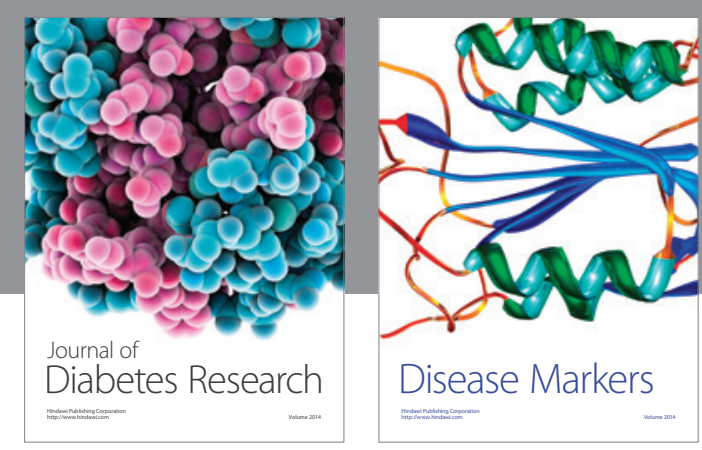

Disease Markers
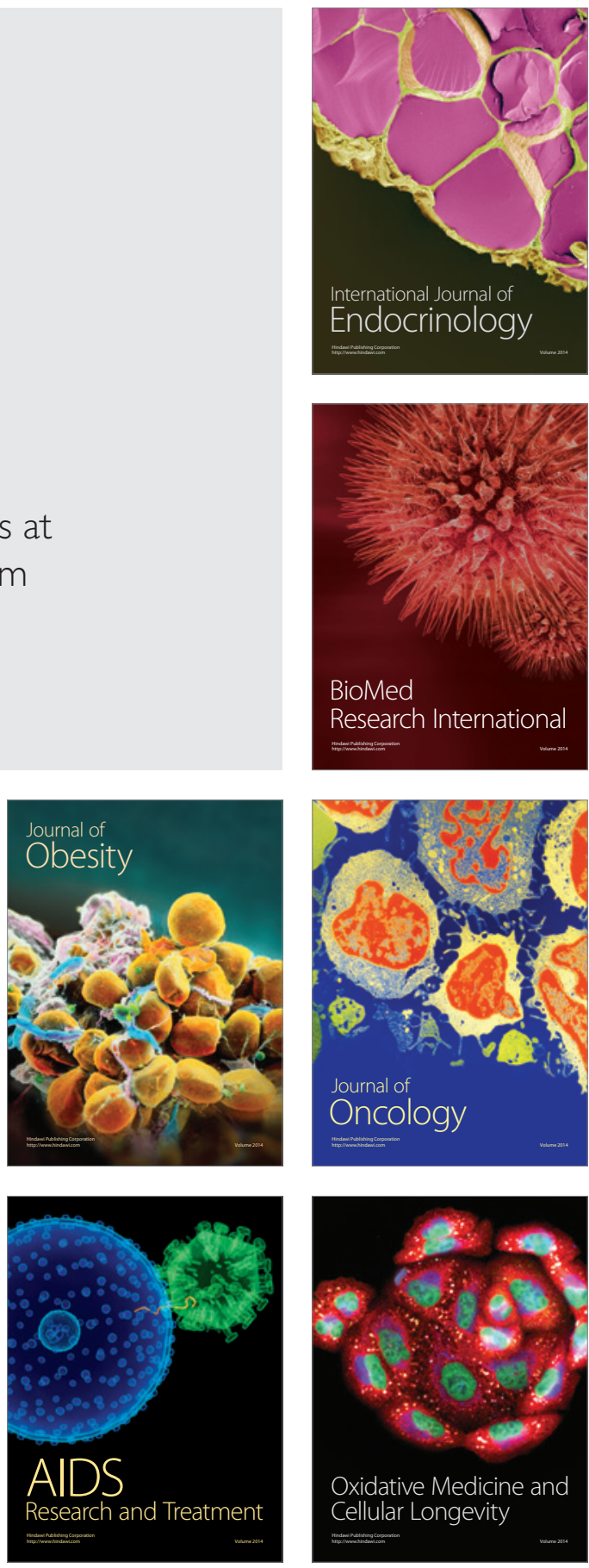